Supporting Information

\title{
Single-walled carbon nanotubes: Efficient nanomembranes for separation and on-board vehicle storage of hydrogen and methane mixture at room temperature?
}

Piotr Kowalczyk ${ }^{\mathrm{a}, \mathrm{c}^{*}}$, Lorenzo Brualla ${ }^{\mathrm{b}}$, Andrzej Żywociński ${ }^{\mathrm{a}}$ and Suresh K. Bhatia ${ }^{\mathrm{c}^{*}}$

${ }^{a}$ Department III, Soft condensed matter, Institute of Physical Chemistry of the Polish Academy of Sciences

${ }^{\mathrm{b}}$ Facultat de Física (ECM), Universitat de Barcelona, Diagonal 647, 08028 Barcelona, Spain

${ }^{c}$ Division of Chemical Engineering, The University of Queensland, St. Lucia, Qld 4072, Australia

\section{The Journal of Physical Chemistry B}

Number of pages: 7

Number of figures: 6

Number of movies: 2 


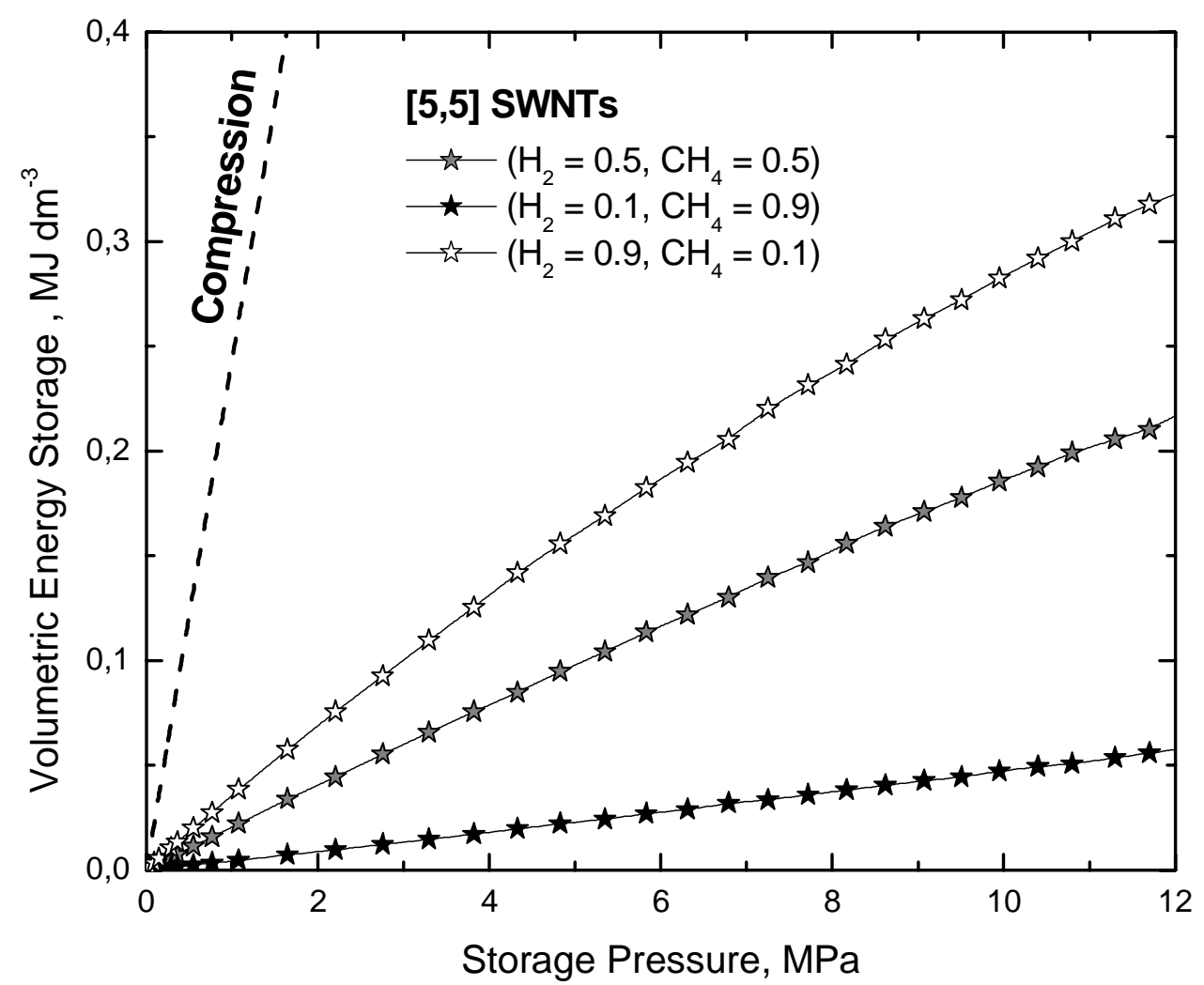

Figure 1S. Impact of the bulk hydrogen and methane mixture composition at $293 \mathrm{~K}$ for the volumetric energy stored in the idealized bundle of [5,5] SWNTs. The inter-tube distance for idealized bundles of [5,5] SWNTs was assumed $4 \AA$ A. Dashed line corresponds to the volumetric energy of the compressed equimolar mixture of hydrogen and methane. 


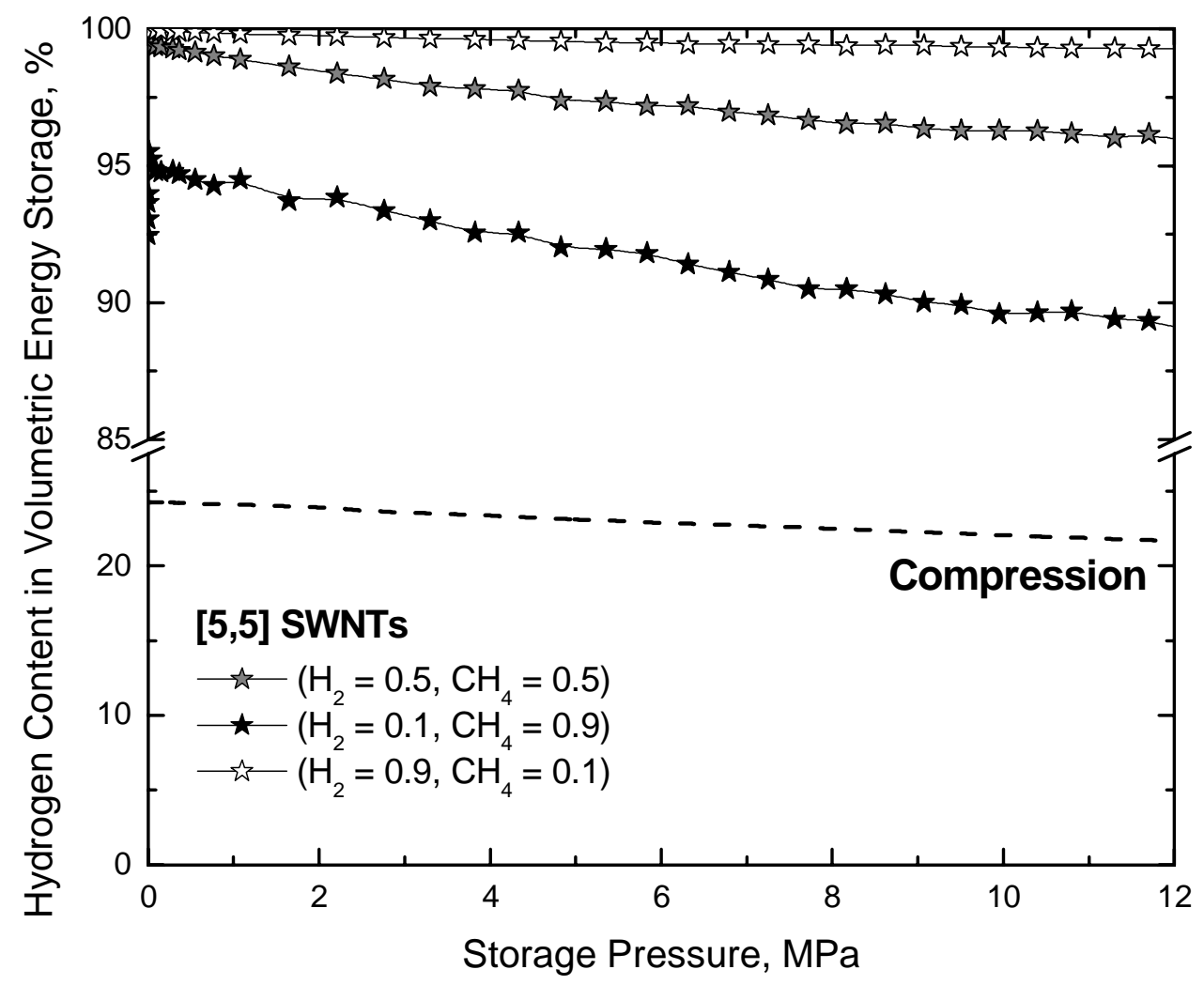

Figure 2S. Impact of bulk hydrogen and methane mixture composition at $293 \mathrm{~K}$ for the hydrogen content in the volumetric energy stored in the idealized bundle of [5,5] SWNTs. The inter-tube distance of the bundle was assumed $4 \AA$. Dashed line corresponds to the contribution of hydrogen to the volumetric energy of the compressed equimolar mixture of hydrogen and methane. 


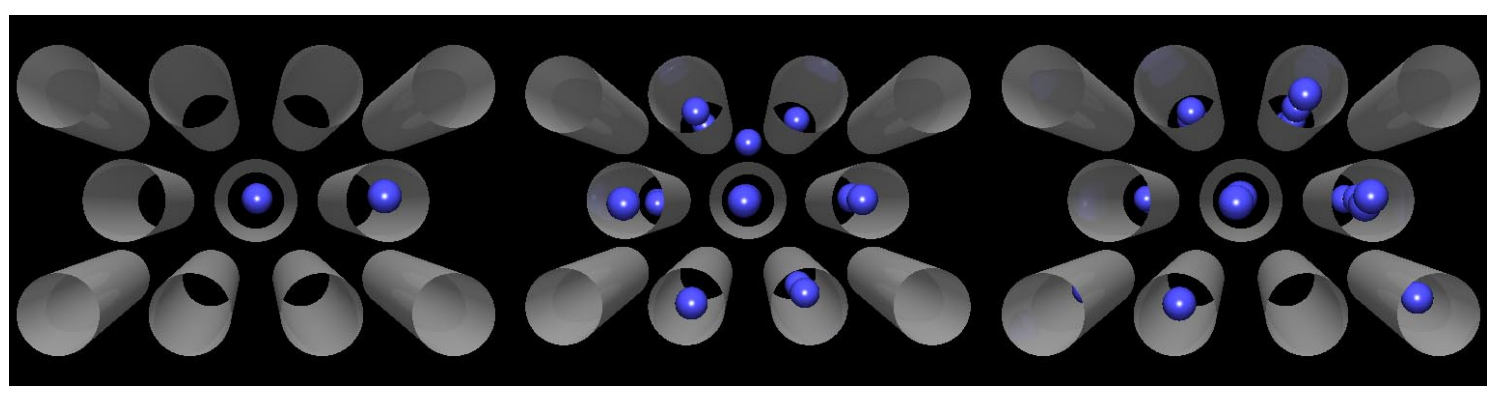

Figure 3S. Equilibrium snapshot of hydrogen and methane mixture for different molar ratio of hydrogen and methane in the bulk phase (form left to right: $x_{H_{2}}=0.1, x_{C_{4}}=0.9$; $\left.x_{\mathrm{H}_{2}}=0.5, x_{\mathrm{CH}_{4}}=0.5 ; x_{\mathrm{H}_{2}}=0.9, x_{\mathrm{CH}_{4}}=0.1\right)$ at $293 \mathrm{~K}$ and $12 \mathrm{MPa}$. The inter-tube distance for idealized bundle of $[5,5]$ SWNTs was assumed $4 \AA$. 


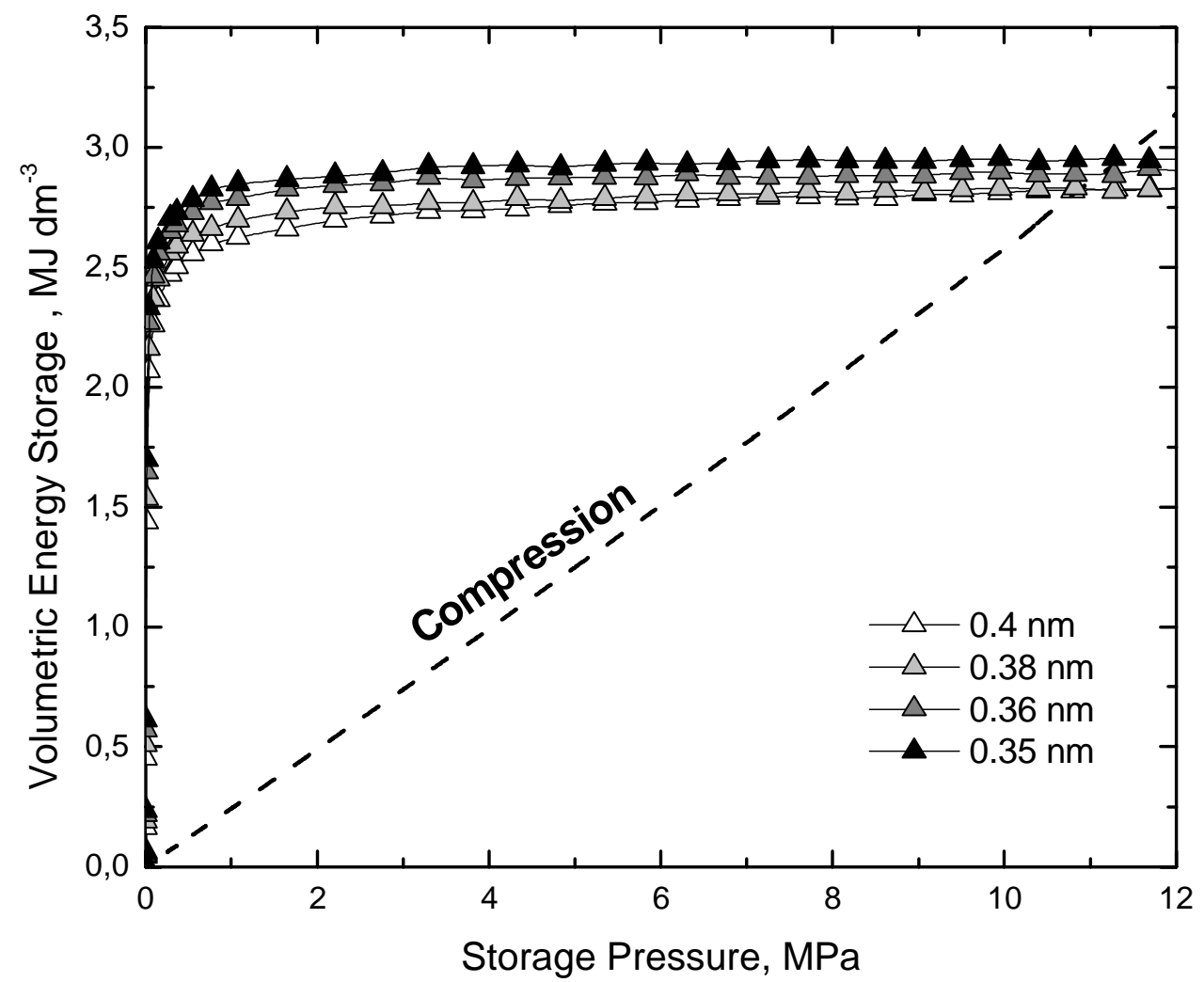

Figure 4S. Impact of the inter-tube distance on the volumetric energy stored from equimolar mixture of hydrogen and methane in the idealized bundle of [6,6] SWNTs. Dashed line corresponds to the volumetric energy of the compressed equimolar of hydrogen and methane 


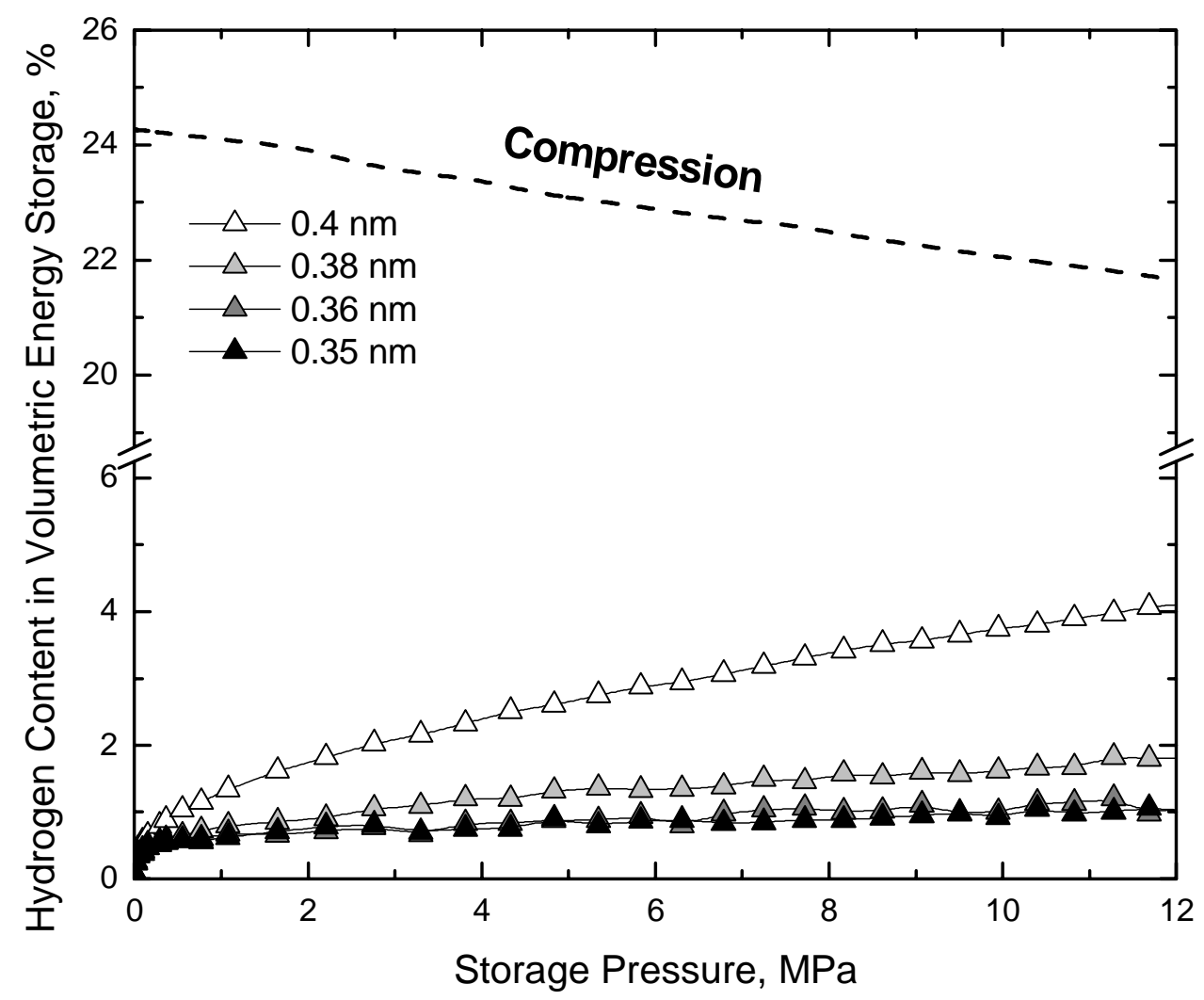

Figure 5S. Impact of the inter-tube distance on the hydrogen content in the volumetric energy stored from equimolar mixture of hydrogen and methane in the idealized bundle of $[6,6]$ SWNTs. Dashed line corresponds to the contribution of hydrogen to the volumetric energy of the compressed equimolar of hydrogen and methane. 


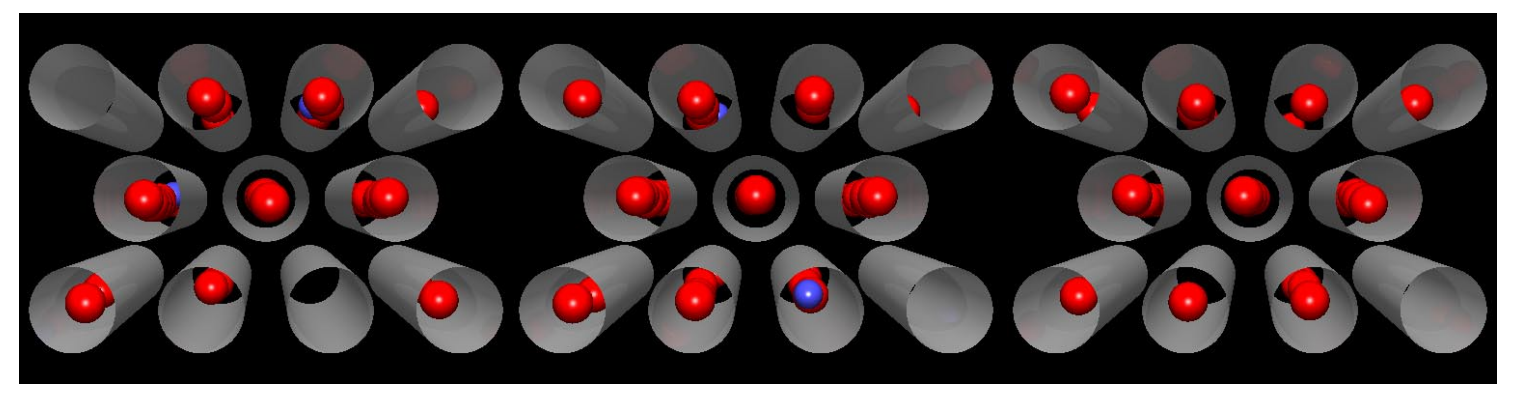

Figure 6S. Equilibrium snapshot of hydrogen and methane mixture for different molar ratio of hydrogen and methane in bulk phase (form left to right: $x_{\mathrm{H}_{2}}=0.9, x_{\mathrm{CH}_{4}}=0.1 ; x_{\mathrm{H}_{2}}=0.5$, $\left.x_{\mathrm{CH}_{4}}=0.5 ; x_{\mathrm{H}_{2}}=0.1, x_{\mathrm{CH}_{4}}=0.9\right)$ at $293 \mathrm{~K}$ and $12.2 \mathrm{MPa}$. The inter-tube distance for idealized bundle of $[6,6]$ SWNTs was assumed $3.5 \AA$. 